\title{
O PESO DO SOFRIMENTO PEDAGÓGICO EM EPISÓDIOS E HISTÓRIAS DE VIDA
}

\author{
THE BURDEN OF PEDAGOGICAL SUFFERING IN EPISODES AND LIFE HISTORIES
}

\author{
Gysele da Silva Colombo Gomes ${ }^{1}$ \\ 1 Universidade do Estado do Rio de Janeiro (UERJ), São Gonçalo, RJ, Brasil \\ gysacolombo@gmail.com
}

Recebido em 5 out. 2018

Aceito em 22 nov. 2018

\begin{abstract}
Resumo: O objetivo principal do presente estudo foi discutir a forma como participantes de um curso de pós-graduação lato sensu - três professoras brasileiras de língua inglesa em formação continuada - constroem discursivamente o sofrimento do professor. Buscou-se também enfocar a coerência apresentada pelas professoras participantes para a associação do vocábulo sofrimento a seu significado etimológico. Norteada pelos parâmetros da Sociolinguística Interacional (RIBEIRO\&GARCEZ, 2002), o referencial teórico adotado na pesquisa tem como base os estudos das narrativas orais (LABOV, 1972; [1967] 2003; BASTOS, 2005; 2008; 2015) e as histórias de vida (LINDE, 1993). Trata-se de uma pesquisa de paradigma qualitativo e interpretativista (DENZIN; LINCOLN, 2006; ERICKSON, 1986; MINAYO, 2002; ANDRÉ, 2008), cujos dados foram gerados com o uso de entrevistas como atividades reflexivas com potencial exploratório (ARPE) em conformidade às propostas da Prática Exploratória (ALLWRIGH, 1991; 2003c; 2006; MILLER, 2012; 2010; MORAES BEZERRA, 2007). O sofrimento é caracterizado como a dificuldade em ser professor devido à discriminação e ao menosprezo social; e como o resultado da ratificação do senso comum, do produto de políticas sociais e educacionais, em construções de idealização profissional social não verbalizadas. Os resultados alcançados laçam luz à premente necessidade de se promover encorajamentos para resistência e sobrevivência à desigualdade e às injustiças sociais.
\end{abstract}

Palavras-chave: Narrativas orais. Prática Exploratória. Formação de professores para Justiça Social.

Abstract: The main purpose of the present study was to discuss the way how three members of a Lato Sensu diploma course on English Language Teaching discursively construct the suffering of being an English teacher. It was also sought to highlight the coherence presented by the participating teachers as for associating the word suffering with its etymological meaning. Based on the parameters of Interactional Sociolinguistics (RIBEIRO \& GARCEZ, 2002), the theoretical framework adopted in the research is based on the studies of oral narratives (LABOV, 1972, [1967] 2003, BASTOS, 2005, 2008, 2015) LINDE, 1993). This is a qualitative and interpretative paradigm research (DENZIN, LINCOLN, 2006; ERICKSON, 1986; MINAYO, 2002; ANDRÉ, 2008), whose data were generated using interviews as reflexive activities with exploratory potential (RAEP) in accordance with the proposals of the Exploratory Practice (ALLWRIGH, 1991; 2003c; 2006; MILLER, 2012; 2010; MORAES BEZERRA, 2007). Suffering is characterized as the difficulty in being a teacher due to discrimination and social neglect; and as the result of the ratification of common sense, the product of social and educational policies, in unverbalized social professional ideational constructions. The results achieved shed light on the urgent need to promote encouragement for resistance and survival to social inequality and injustices.

Keywords: Oral narratives. Exploratory Practice. Teacher Training for Social Justice.

\section{INTRODUÇÃO}

Em tempos de grandes preocupações acerca de questões sociais e educacionais, em que o pano de fundo é o cenário beligerante em nosso país, 
deparamo-nos com o paradoxo entre a abordagem da Formação de Professores para a Justiça Social (FPJS) e o latente sentimento na formação inicial e continuada de professores: o sofrimento profissional.

A FPJS, conforme salienta Zeichner (2008, p. 11), que "parece ter se tornado o rótulo escolhido por faculdades e universidades formadoras de docentes", busca preparar professores para a missão de contribuir para menor desigualdade social. Corroborando essa visão, nessa missão, como professores de inglês, cabe-nos similarmente a tarefa destacada por Zeichner (2008) - de preparar professores para lecionarem em sociedades em que formas crescentes de responsabilidade têm sido impingidas às escolas.

Seria, no entanto, tal missão exequível dentro de nossa contundente realidade profissional? Diante de tantas disparidades e injustiças sociais, considero relevante retomar uma questão abordada em minha tese de doutoramento: o sofrimento que emerge nas narrativas orais de três professoras de inglês em um curso de formação continuada.

O estudo é norteado à luz da imbricação da perspectiva da FPSC (DINIZPEREIRA; ZEICHNER, 2008) e da Prática Exploratória (ALWRIGHT, 1991; 2003c, 2006; ALLWRIGTH; MILLER; 2012; 2010). Essa perspectiva é justificada pelo fato de que ambas abordagens entendam que escolas e educação são lócus de prática de democracia, em que professores formadores e em formação promovem ações para a busca constante por entendimentos tanto de natureza cognitiva como de crítica social.

Nessa ubiquidade pedagógica que se espera emergir na comunhão da Prática Exploratória (doravante, PE) e a da FPJS, todo as práticas discursivas devem visar à contribuição para a ampliação de mecanismos reflexivos para o desenvolvimento mútuo daqueles envolvidos em qualquer processo de ensino-aprendizagem particularmente, para que possam entender que a principal tarefa da educação é auxiliar a todos na capacidade de análise de suas experiências com o propósito de identificar questões pertinentes ao agir social de cada indivíduo. Consequentemente, ao promover condições de identificar problemas ou injustiças em suas vidas que possam causar sofrimento, torna-se possível gerar entendimentos para resistência e sobrevivência, não obstantes os percalços estabelecidos por agentes da desigualdade social. 


\section{O SOFRIMENTO}

Minha percepção acerca da origem da palavra sofrimento foi concebida há bastante tempo, nas aulas da graduação na UERJ - uma daquelas aulas de Latim nos dois últimos tempos das segundas à noite quando, recém-adaptados à abertura política dos anos oitenta, nossas esperanças eram maiores do que o presente 'temer' da atualidade. Etimologicamente falando, o termo derivado do latim, sufferre, era designado para referir a quem estava "sob ferros", acorrentado, submetido à força (escravo ou prisioneiro). Dessa forma, a origem do "sofrimento": palavra pela qual melhor se traduz a infelicidade contínua, intensa e irremediável. É também o vocábulo que designava a opressão, a submissão, a situação da criatura submetida ao poder do opressor ou da "ferramenta", que trazia os infortúnios capazes de lhe "ferir" corpo e alma.

O sofrimento tem despertado crescente interesse em pesquisas das mais diversas áreas, como da psicologia, sociologia, antropologia, filosofia, dos estudos da linguagem ou, ainda, sobre narrativas jornalísticas profissionais - tais como os trabalhos: Narrativas de Sofrimento no Jornalismo Impresso: a construção de cenas e o lugar dos sujeitos, dos autores Danila Gentil Rodriguez Cal e Leandro Rodrigues Lage; e Narrativas do Sofrimento do Trabalho de um Policial Militar Afastado de Almerinda Maria Skeff Cunha e Liliam Deisy Ghizoni.

Como menciono em trabalho anterior (COLOMBO GOMES, 2014), o sofrimento profissional remete-me ao trabalho de construção do sofrimento dos profissionais da saúde de Bastos (2008), em que a autora compreende o sofrimento como uma experiência social, que inclui condições tais quais: questões de saúde, religião, ética, direito, para citar algumas. Assim como Bastos (2008), entendo que o sofrimento social, da mesma forma que o sofrimento profissional, remete a um conjunto de problemas que têm origem nos males que forças sociais podem infringir à experiência humana. Saliento que observo no sofrimento profissional de professores a necessidade de ações associadas à formação educacional alicerçadas na FPJS e na PE. 


\section{PROCEDIMENTOS TEÓRICO-METODOLÓGICOS}

Este estudo qualitativo de cunho etnográfico é um recorte de minha tese de doutoramento e seu aporte teórico está centrado na área da Sociolinguística Interacional (RIBEIRO; GARCEZ, 2002), nos estudos das narrativas (LABOV, 1972; BASTOS, 2005; 2008) e em histórias de vida (LINDE, 1993). Dentre os temas abordados na tese, devido à relevância atribuída ao tema sofrimento em associação ao magistério, proponho revisitar as narrativas em que as professoras participantes abordam o sofrimento do professor.

Inspirei-me no modelo laboviano clássico (LABOV, 1972), seguindo o critério mínimo necessário para decidir se o segmento de fala selecionado era uma narrativa - a presença de pelo menos dois eventos em sequência temporal. No entanto, assim como Bastos (2008, p. 78), entendi que os eventos não precisariam "estar necessariamente no passado, nem articulados sintaticamente em orações independentes, com verbos de ação no passado".

Quanto ao instrumento para a geração de dados, destaco que foram observadas as narrativas orais que emergem em três atividades reflexivas com potencial exploratório (ARPE, cf. MORAES BEZERRA, 2007). Essas ARPEs foram feitas em forma de sessões de entrevistas vídeo-gravadas em um curso de formação continuada em 2011', nas quais o sofrimento do professor é abordado. Segui, como critério para seleção ou ordem de análise dessas narrativas dialogicamente construídas, a forma como esse sentimento é construído por três das professoras participantes.

\section{DISCUSSÃO E ANÁLISE}

A primeira narrativa abordando o tema que me proponho analisar foi a que emerge nas histórias contadas por llca, como pode ser observada nas partes destacadas no excerto 1.

1 Para maiores esclarecimentos sobre o contexto do curso de formação continuada vide COLOMBO GOMES (2014). 


\section{EXCERTO 1}

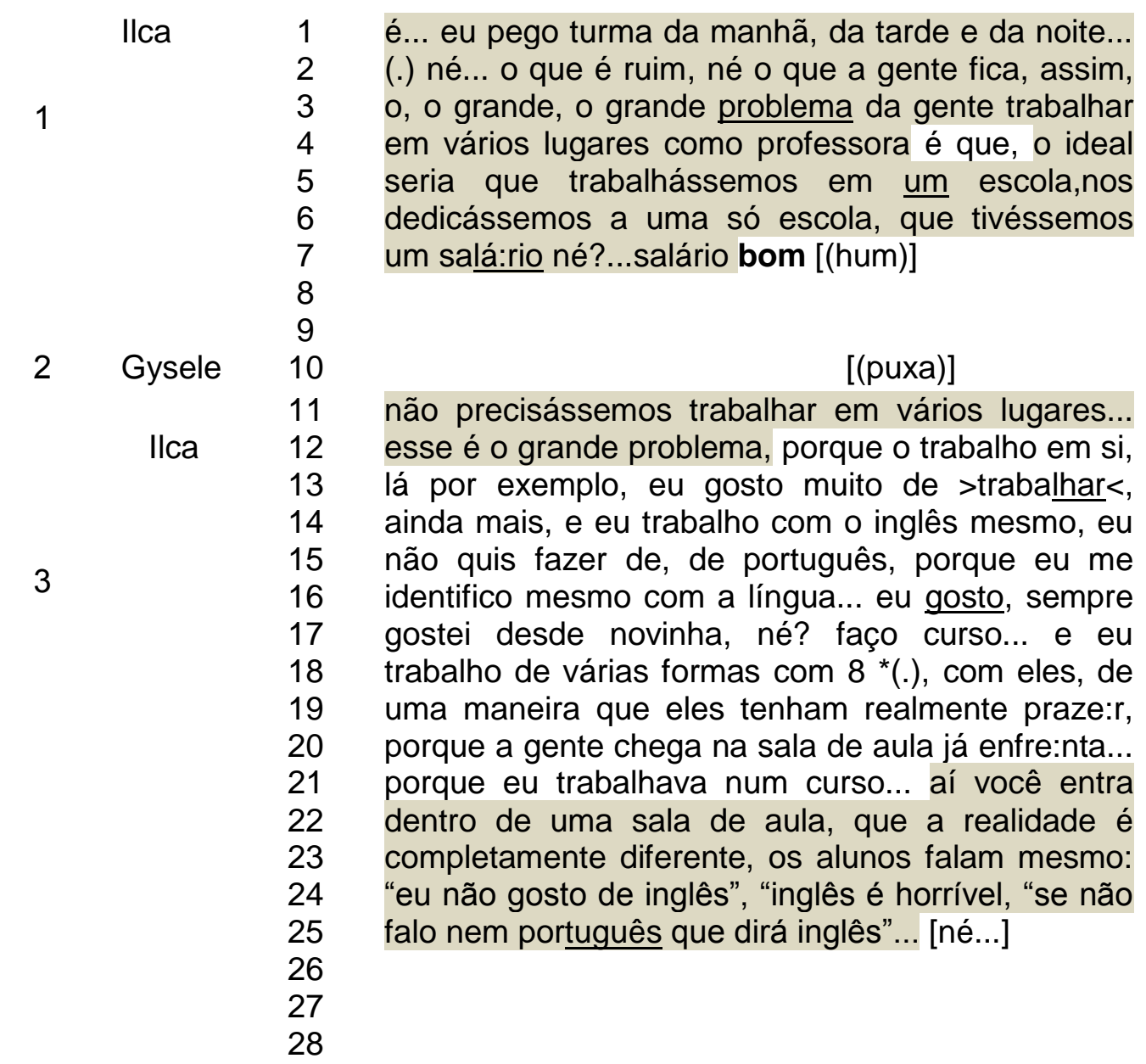

Nessas histórias, o sofrimento foi construído como a dificuldade em ser professor, como discriminação e menosprezo social, e como o sofrimento da mãe professora. A primeira delas tem como ponto a dificuldade em ser professor. Tratase de uma construção em três turnos, dois deles de llca e um com minha participação com uma fala sobreposta, que funciona como incentivo para a professora manter o piso conversacional.

É pertinente notar que, ainda que tentasse propiciar uma conversa natural, minha identidade de pesquisadora sobrepõe-se à identidade de participante do curso e, de forma claramente assimétrica, dou à professora todas as chances de manter o seu turno de fala. A finalidade de agir dessa forma pareceu-me inadvertida no momento da gravação. Todavia, ao rever a gravação, percebo que procuro evitar 
distrair a professora de sua tarefa de narrar e demonstrar-lhe meu interesse em ouvi-la consciente da forma como desejo enquadrar (GOFFMAN, 1974) a interação. Para isso, restrinjo-me apenas a exclamar surpresa (puxa!) com a finalidade de não tomar o turno.

Ao longo da experiência de vida no excerto 1, llca discorre sobre as características de seu sofrimento - a itinerância ("não precisássemos trabalhar em vários lugares..." - linha 1-2,), a dificuldade de trabalhar em três turnos e o stress ("é... eu pego turma da manhã, da tarde e da noite... (.) né... o que é ruim né, o que a gente fica, assim, o, o grande, o grande problema da gente trabalhar em vários lugares como professora" - linhas 1-5, excerto 1), a noção comum da baixa remuneração ("e que tivéssemos um salá:rio, né?" - linhas 7-8), e da responsabilidade do professor em promover o interesse de aprender dos alunos ("aí você entra dentro de uma sala de aula, que a realidade é completamente diferente, os alunos falam mesmo: "eu não gosto de inglês", "inglês é horrível, "se não falo nem português que dirá inglês"..." - linhas 23-28).

A narrativa é prefaciada com "é... eu pego turma da manhã, da tarde e da noite... (.) né... o que é ruim né, o que a gente fica, assim, o, o grande, o grande problema da gente trabalhar em vários lugares como professora" (linhas 1-5), o que me conduz ao entendimento de que a razão pela qual llca me conta essa história é querer compartilhar comigo a dificuldade em ser professora. Esse prefácio, com a avaliação do que ela faz (é "ruim" - linha 2) e que intensifica o seu sofrer com a avaliação de seu trabalho que tem "o grande problema" (linhas 3-4) é a forma como a professora enquadra o que será dito e sinaliza para mim, sua interlocutora, como devo interpretar o que virá - o sofrimento de uma professora itinerante - em que o sofrimento enfrentado parece ser apenas um sentimento local, de um único indivíduo.

É relevante observar que, ainda que seja uma história de dificuldades e sofrimento da profissão, existem avaliações externas como "eu gosto, sempre gostei desde novinha" (linhas 7-8, excerto 1) e "e eu trabalho de várias formas com (.), com eles, de uma maneira que eles tenham realmente praze:r" (linhas 9-11). Essas avaliações externas trazem a percepção de que, embora exista sofrimento no magistério, Ilca dignamente trabalha para a promoção do processo ensinoaprendizagem com prazer. Além disso, a professora participante também aponta 
soluções para o sofrimento da profissão ("o ideal seria que nós trabalhássemos em uma escola, nos dedicássemos a uma só escola, e que tivéssemos um salá:rio né... bom [(hum)]" linhas, 5-9).

Em outro momento na ARPE, Ilca enfoca o sofrimento da discriminação social que um professor pode enfrentar. Temos, novamente, uma breve narrativa não canônica, com forte carga dramática. Desta vez, no excerto 2, o trabalho narrativo de llca tem o caráter de exemplificação, pois a professora narra hipoteticamente um evento, no qual se encontram diversos profissionais liberais e o professor sofre com a discriminação e o desprezo social.

\section{EXCERTO 2}

llca 1 [exatamente...] (.) é o me::smo problema né, nós somos discrimina::dos, nós somos menosprezados algumas vezes, POR uma classe alta, por exemplo, quando você ta num, num meio, conversando né, você fala que é professora e tudo, e você né, é praticamente NADA, porque médico, advogado, né, eles acham que professor é a profissão de um nada, como ele eles tivessem que ter passado por nós pra, pra aprender=

10

As avaliações de llca dão a sua história o sentido concreto de sofrimento social. Ao exemplificar que em determinados eventos os professores são sociodiscursivamente construídos como profissionais discriminados e menosprezados ("nós somos discrimina::dos, nós somos menosprezados algumas vezes, POR uma classe alta" - linhas 2-4), Ilca ratifica o senso comum como forma de dar coerência (LINDE, 1993) ao que deseja compartilhar comigo: seu sofrimento por não receber o reconhecimento social que julga merecer. A ação dramática de Ilca, ao construir o professor com as avaliações "discrimina::dos" (linha 2) e "menosprezados algumas vezes" (linha 3) ganha mais carga com a estruturação da oração na voz passiva, que tem a preposição "por" introduzindo o agente da passiva pronunciada em um tom mais alto e forte.

Faz-se necessário observar que, embora o agente da passiva seja um termo facultativo, no discurso da professora seu papel na oração é acentuado; segundo llca, os professores são discriminados e menosprezados por uma classe diferente, que Ilca julga ser mais "alta" do que a sua. O ápice das avaliações feitas é quando 
Ilca constrói a identidade dos professores em interação, pois ela acredita que, ao se anunciar professora, ela se sente desvalorizada ("quando você tá num, num meio, conversando né, você fala que é professora e tudo, e você né, é praticamente NADA," - linhas 4-7).

Um ponto merecedor de atenção nessa breve narrativa da professora é sua projeção como profissional que sofre discriminação, menosprezo e que "é praticamente nada" ser construída na interação, mas, de acordo com seu relato, essa construção social não é verbalizada. Creio ser interessante que, em sua história, nenhum outro profissional diz à professora que ela não é nada; seu sofrimento surge como o resultado da ratificação do senso comum, do produto de políticas sociais e educacionais de nosso país.

Na narrativa do excerto 3, llca aborda o sofrimento de uma outra forma - esse sentimento é construído no outro, sua mãe. Com minha colaboração, llca conta uma história para justificar o motivo segundo o qual não queria ser professora. A história é composta em sete turnos assimétricos, como se observa:

\begin{tabular}{|c|c|c|}
\hline & & EXCERTO 3 \\
\hline Ilca & 1 & [isso, minha mãe] é professora né... \\
\hline Gysele & 2 & [aham...] \\
\hline Ilca & $\begin{array}{l}3 \\
4 \\
5 \\
6\end{array}$ & $\begin{array}{l}\text { professora de português... então eu falava assim: } \\
\text { "eu não, não vou ser professora não", porque eu via } \\
\text { (som agudo) minha mãe (som agudo) coitada pra } \\
\text { criar a gente... (.) }\end{array}$ \\
\hline Gysele & 7 & por que que você quis ser...?= \\
\hline Ilca & $\begin{array}{c}8 \\
9 \\
10 \\
11 \\
12 \\
13\end{array}$ & $\begin{array}{l}\text { = é::, ai é POR QUE né? eu cheguei a entrar pra uff } \\
\text { pra fazer ciências contábeis... mas eu tranquei, não } \\
\text { gostei... porque quando eu passei, é... eu fiz letras, } \\
\text { passei pra letras, e passei pra ciências contábeis, } \\
\text { aí (.) entrei nos dois (.) pra ver... }\end{array}$ \\
\hline Gysele & $\begin{array}{l}14 \\
15 \\
16 \\
17\end{array}$ & $\begin{array}{l}\text { é, me explica uma coisa... você, é, tinha uma } \\
\text { indecisão sobre a sua carreira, ou você fez pra "vou } \\
\text { fazer ciências contábeis, se eu não passa:r eu fico } \\
\text { em letras"? }\end{array}$ \\
\hline Ilca & $\begin{array}{l}19 \\
20 \\
21 \\
22 \\
23 \\
24 \\
25 \\
26\end{array}$ & $\begin{array}{l}\text { não... eu simplesmente adora:va inglês, mas eu } \\
\text { não queria ser professora... eu, e, é... eu entrei pra } \\
\text { letras, fiz pra letras, porque a gente sempre coloca } \\
\text { uma segunda opção... mas mesmo entrando na } \\
\text { faculdade, mesmo se eu cursasse em letras, né, só } \\
\text { como... eu não iria, mesmo que eu não tivesse } \\
\text { passado pra ciências contábeis e ficasse só pra } \\
\text { letras... eu não iria trabalhar como professora, eu }\end{array}$ \\
\hline
\end{tabular}


27 iria pela área de línguas mas pra outra coisa falava:

28 "não mãe, não quero ganhar pouco mas ai, é... eu

29 detestava mesma essa idéia de "ah, vou ser

30 professora" porque eu vi o quanto minha mãe suou

31 pra poder pagar um curso, os cursos, e colégio...

32 eu estudei em escola pública, mas o quanto ela

33 suou pra poder pagar as coisas que a gente né...

34 também é professora do estado... eu o não...

35 quero... né...[hhh] falava pra ela...

36

37

38

A narrativa analisada no excerto 3 apresenta dois pontos principais: a razão pela qual Ilca não queria ser professora e o sofrimento de sua mãe por ser professora. Trata-se de uma narrativa mais canônica, na qual podemos identificar uma sequência de ações no passado ao longo da interação que ocorre entre as linhas, que são: (i) "então eu falava assim: "eu não, não vou ser professora não"” (linhas 3-4); (ii) "porque eu via (som agudo) minha mãe(som agudo) coitada pra criar a gente..." (linhas 5-6); (iii) "eu cheguei a entrar pra uff pra fazer ciências contábeis.." (linhas 9-10); (iv) "mas eu tranquei" (linhas 9-10); (vi) "não gostei..." (linha10) ; (vii) "eu simplesmente adora:va inglês" (linha 19); (viii) "mas eu não queria ser professora..." (linha 19-20) (ix) "eu, e, é... eu entrei pra letras," (linhas 20-21).

Sob o prisma dos estudos labovianos, noto que não há nessa narrativa muitos detalhes da orientação; contudo, está implícito que a história aconteceu na adolescência de Ilca, começando na época que estava se preparando para ingressar na faculdade e terminando quando ela vai cursar Letras - "eu, e, é... eu entrei pra letras." (linhas 20-21). A única menção sobre o local onde a história acontece é feita quando a narradora comenta que "chegou a entrar para a UFF" "eu cheguei a entrar pra uff pra fazer ciências contábeis..." (linhas 8-9) - o que se subentende que o local é a cidade de Niterói, e a única personagem é a narradora, que apenas relata a existência de sua mãe e de seu sofrimento.

Observei que, inicialmente, na narrativa do excerto 3, llca busca organizar argumentos para fazer com que eu, sua interlocutora, entenda seu desejo de não ser professora. Percebo o caminho que ela percorre para mostrar esse desejo desde seu resumo, que parecia anunciar que ela queria ter outra profissão. A complicação de sua história acontece quando deixa vir à tona sua grande indecisão que foi cursar 
Ciências Contábeis ou Letras ("eu cheguei a entrar pra uff pra fazer ciências contábeis..." - linhas 8-9), e a resolução da história é resolver cursar Letras ("eu, e, é... eu entrei pra letras" - linha 10).

Na ocasião da gravação, quando ouvi a resolução da história, pensei que llca já tinha dado como terminada sua história, porém, para minha surpresa, a professora continuou seu trabalho narrativo. Ela continua usando sua narrativa para justificar por que não queria ser professora e, desta vez, constrói o sofrimento da mãe para não ingressar no magistério ("eu não iria trabalhar como professora, eu iria pela área de línguas mas pra outra coisa...falava: "não mãe, não quero ganhar pouco mas ai, é... eu detestava mesma essa idéia de "ah, vou ser professora" porque eu vi o quanto minha mãe suou pra poder pagar um curso, os cursos, e colégio... eu estudei em escola pública, mas o quanto ela suou pra poder pagar as coisas que a gente né... também é professora do estado..." - linhas 27-36).

Um dado pertinente para meu estudo, encontrado na ficha cadastral preenchida individualmente para a inscrição do curso de especialização, foi conhecer a profissão dos pais das participantes. Percebo no discurso de llca a valorização ao sacrifício de sua mãe, que "suou" para educar suas filhas. Nesse trecho, paradoxalmente, se por um lado, o sofrimento da mãe da professora para poder educar suas filhas foi árduo; por outro, parece-me que esse pesar serviu para causar dois sentimentos fortalecedores por sua mãe: admiração e respeito.

No que se refere a esses sentimentos, em primeiro lugar, Ilca contempla sua mãe com apreço, aprecia o modelo maternal e profissional em quem deseja mirarse. Em segundo, entendo o respeito da professora por esse modelo como algo determinante para o acontecimento de algo ou a existência de algum fato: sua escolha profissional - professora como a mãe.

Diferente das formas como llca constrói o sofrimento, Christina aborda esse sentimento como uma forma de poder. A professora afirma que tinha o poder de causar sofrimento a seus professores. E, segundo a própria, essa forma de sofrimento é um sentimento causado pelo comportamento dos alunos em professores.

É fato reconhecido que o problema disciplinar e a pedagogia têm representado uma luta de sofrimento constante há um longo período. Friso que me refiro, neste texto, à pedagogia crítica a fim de contemplar a imbricação dos pilares do 
conhecimento, da autoridade e do poder. Busco, dessa forma, confrontar Cristina aluna e Cristina professora sob o viés do poder como forma de causar e mitigar o sofrimento no ambiente escolar.

O poder, segundo Foucault (1982), só existe quando é colocado em ação. Aliás, segundo esse autor (Ibidem) a relação de poder só é articulada por meio de duas condições. A primeira delas é que o indivíduo, sobre o qual o poder se exerce, seja nitidamente visto como alguém que age socialmente. A segunda condição é de que reações ou resultados surjam a partir das relações entre o indivíduo que exerce o poder e aquele sobre o qual o poder é exercido. Entende-se, então, que para o poder existir é necessário que haja uma resistência.

É sabido que "o poder social é uma característica da relação entre grupos, classes ou outras formações sociais, ou entre pessoas na qualidade de membros sociais" (VAN DIJK, 2010, p. 41). Compreendo que uma forma de poder pessoal não seja tão relevante para uma análise sistemática do papel do poder no discurso enquanto interação social. Entretanto, se as relações de poder manifestam-se na interação, analisar uma narrativa nos oferece a possibilidade de olhar criticamente 0 poder no discurso de um relato de uma experiência interacional.

Assim, tomo como objeto a tensão de causar e mitigar sofrimento, cuja tessitura é urgida na curta narrativa destacada no excerto 4. Nela é possível observar o trabalho discursivo em que Christina se engaja para se projetar como aluna que exerce o controle do sofrimento imposto aos professores e como seu exercício é replicado por seus alunos atuais.

\section{EXCERTO 4}

$\begin{array}{lll}\text { Christina } & 1 & \text { [...] meus professores sofreram muito, fazia muita } \\ & 2 & \text { bagunça na sala, mas eu sempre procurei prestar } \\ 3 & \text { atenção na hora que tinha que prestar atenção, é } \\ 4 & \text { isso que eu vejo mu::ita dificuldade hoje em dia [...] } \\ & 5 & \end{array}$

Após uma inesperada pausa em nossa interação, Christina destaca que, apesar de sempre ter prestado atenção nas aulas, seus professores "sofriam" com ela e que agora, como professora, enfrenta o sofrimento de lidar com alunos que fazem muita bagunça e são desatentos. Nota-se que ao se referir aos professores, 
Christina estabelece pontos que caracterizam uma relação de poder (em conformidade com FOUCAULT, 1982) que entendo como uma fatalidade do contexto educacional destacando um sistema de diferenciações, tipos de objetivos, o meio para viabilizar o controle e o grau de racionalização para manutenção do controle.

Christina assevera que, quando era aluna, tinha controle sobre a intensidade do sofrimento que ela causava a seus professores. Seu meio para a viabilização do controle era a bagunça e o objetivo era abafar a voz do professor. Tratava-se de uma aluna que não via o quanto dificultava o trabalho de seus mestres.

Quanto ao grau de racionalização para manutenção do controle, Christina costumava gerenciar seu comportamento para não interferir em sua aprendizagem o que era uma ação elaborada visando a um benefício próprio. Assim sendo, durante as explicações, Christina procurava comportar-se e com isso mitigar o sofrimento que o desconforto do mau comportamento trazia para a aula.

Hoje, por sua vez, como professora encontra muita dificuldade em lidar com a falta de comportamento e sofre com isso. É interessante observar que a escolha de como se alinhar - ora como aluna, ora como professora - adotada por Cristina envolve questões que abarcam a disciplina, o controle e o ensino-aprendizagem como forma de promover sofrimento.

Em relação à analise da narrativa sob o prisma laboviano, trata-se de uma sequência de orações narrativas, das quais a primeira delas é um resumo da história (meus professores sofreram muito). A narrativa apresenta a ausência de orientação explícita, contudo, é possível perceber que a história ocorre no passado pelas escolhas de verbos no modo indicativo no pretérito perfeito (sofreram, procurei) e no pretérito imperfeito (fazia, tinha). As avaliações, que dão carga dramática à história, no entanto, são feitas com verbos no passado e no presente - se no passado como aluna fazia bagunça, no presente vê muita dificuldade em lidar com a bagunça causada pelos alunos. Isso significa que avaliação sobre ser aluna e fazer seus professores sofrerem opõe-se ao presente, período em que Christina tem um novo papel social nas interações escolares.

O ponto da história é o sofrimento, o motivo da professora narrar essa experiência é expor como professor sofre. Após a conclusão da ação complicadora (fazia muita bagunça na sala), temos como resolução a evidência de que Christina 
podia fazer bagunça, mas, como forma de respeito às relações da sala de aula institucionalizadas e legitimando o poder dos professores, prestava atenção nas aulas. Resta-nos, por fim, entender que para Christina, em seu cotidiano, a "dificuldade hoje em dia" é ver que seus alunos não agem da mesma forma.

A última forma de sofrimento mencionada foi abordada por Simone, no excerto 5. O sofrimento ao qual Simone se refere é aquele causado por seus colegas de profissão, que, segundo a professora, ao causarem algum desconforto nos alunos criam lembranças negativas e indiretamente tornam seu trabalho mais difícil. Dessa forma, esse é o sofrimento que alguns professores causam aos alunos e a outros colegas de profissão.

\section{EXCERTO 5}

$\begin{array}{ccl}\text { Simone } & 1 & \text { tem, tem... e infelizmente eu tenho curado as vezes } \\ 2 & \text { cicatrizes de outros professores que a minha } \\ 3 & \text { vontade é pegar aquele indivíduo e esganar... } \\ 4 & \text { porque ele queimou meu filme, ele queimou o meu } \\ 5 & \text { trabalho... porque ele fez uma etapa errada, ele } \\ 6 & \text { cometeu um erro na vida daquela pessoa, e que } \\ 7 & \text { aquilo Ihe causou um trauma, uma ferida e agora } \\ 8 & \text { eu tenho que curar a ferida pra que aquela pessoa } \\ 9 & \text { tenha .h, tenha condições de saúde pra poder } \\ 10 & \text { continuar recebendo as minhas apresentações... } \\ 11 & \\ 12 & \end{array}$

Para Simone, o trabalho mal realizado de um professor pode causar danos ao aprendizado ("infelizmente eu tenho curado às vezes cicatrizes de outros professores que a minha vontade é pegar aquele indivíduo e esganar... porque ele queimou meu filme, ele queimou o meu trabalho..." - linhas 1-5) e sofrimento ao aluno e a outros professores que, assim como Simone, enfrentarão barreiras criadas que distanciam os alunos do aprendizado ("porque ele queimou meu filme, ele queimou o meu trabalho... porque ele fez uma etapa errada, ele cometeu um erro na vida daquela pessoa, e que aquilo the causou um trauma, uma ferida e agora eu tenho que curar a ferida pra que aquela pessoa tenha.$h$, tenha condições de saúde pra poder continuar recebendo as minhas apresentações..." - linhas 4-12).

É relevante salientar a dualidade retratada por Simone, vemos em seu relato a ação sofrimento sendo exercida em dois aspectos - alunos e professores que 
causam sofrimento e professor que resgata a dor. Observo neste ponto de análise a relação etimológica da palavra com as ações narradas, pois tanto os alunos como os professores encontram-se "sob ferros", acorrentados, submetido à força social do fazer pedagógico. O sofrimento pode ser causado pela rejeição dos alunos à aprendizagem, bem como pelo agir do profissional que distancia os alunos do aprendizado e pelo professor que se autopenaliza em sua luta para exercer seu papel com dignidade. Destaco essa luta como a infelicidade contínua, intensa e irremediável que o vocábulo sofrimento carrega semanticamente.

Por fim, não pretendo criar generalizações ou afirmar que o sofrimento é comum a todos os professores. Busco, todavia, ressaltar as dificuldades enfrentadas por professores, não só os de Língua Inglesa, mas os das mais diversas áreas.

\section{CONSIDERAÇÕES FINAIS}

Propus-me neste texto a discutir a forma que o sofrimento é construído discursivamente pelas vozes de três professoras em narrativas que emergem em interações pedagógicas durante um curso de especialização. O estudo permitiu-me examinar o desenvolvimento dos tópicos e os pontos de suas narrativas. O tema emergente em nossas histórias e interação foi o sofrimento do professor.

Acredito que a abordagem de sofrimento advenha da conscientização dessas professoras acerca de seu ser-fazer profissional. Agradeço às participantes pela liberdade e o conforto de se posicionarem em relação uma às outras espontaneamente, diferentemente do que em geral acontece em entrevistas de pesquisa. Dessa forma, meu trabalho como pesquisadora pode ser caracterizado convergente ao tipo de pesquisa sobre pessoas e sobre meu contexto profissional, não invasivo e de caráter qualitativo, etnográfico, interpretativista, em que todos estejam envolvidos no trabalho, e que o trabalho seja para a união de todos e para o desenvolvimento mútuo, em consonância com os princípios da Prática Exploratória.

Em tempos críticos e delicados em que a alocação de artifícios educadores e promotores de reflexão entre diferentes necessidades sociais é uma questão vital para professores em formação inicial ou continuada para nosso país, trazer à tona a conscientização do sofrimento profissional é um desafio para obtermos justiça social para aprendizes e professores. 
Sob o aspecto supracitado, tanto a Prática Exploratória como a Formação de Professores para Justiça Social devem dar e receber apoio a todos os envolvidos em processos educativos. Cabe a todos nós lançar nosso olhar crítico sobre o que está acontecendo para podermos trabalhar em prol da liberdade para a diminuição das desigualdades sutis, reforçadas não somente em cotidianos sociais, mas, também em instâncias superiores e governamentais.

Diante do cenário alarmante, com tantas mudanças ocorrendo após um tenso período eleitoral em nosso país, minha análise sobre o tema abordado pelas professoras participantes destaca uma vertente inquietante: a fragilidade e suscetibilidade dos membros da formação inicial e continuada de professores de inglês. Encerro, entretanto, em coadunação com essas professoras ouvidas, salientando que se, por um lado, o sofrimento do professor tem promovido a evasão nos cursos de Letras, o desestímulo à carreira e mudanças de profissão, por outro lado, esse mesmo sofrimento causa, simultaneamente, admiração, respeito e consideração.

\section{REFERÊNCIAS}

ABBAGNANO, N. Dicionário de Filosofia. São Paulo: Martins Fontes, 2000.

ALLWRIGHT, R. L. Exploratory Teaching. Unpublished Paper, Viseu, 1991.

. Exploratory Practice and Academic Research: the Nature of the Interrelationship. Rio de Janeiro, 2003c, mimeo.

. Six Promising Directions in Applied Linguistics. In: GIEVE, S.; MILLER, I. (ed.). Understanding the Language Classroom. New York: Palgrave/McMillan, 2006.

. MILLER, I. K. Burnout and the Beginning Teacher. In: TARONE, E.; SONESON, D.; CHAMOT, A. U.; MAHAJAN, A.; MALONE, M. (ed.). Expanding Our Horizons: Language Teacher Education in the 21st Century. Minneapolis: The Center for Advanced Research on Language Acquisition, 2012.

ANDRÉ, M. E. D. A. Etnografia da prática escolar. Campinas: Papirus, 2008.

BASTOS, L. C. Contando estórias em contextos espontâneos e institucionais - uma introdução ao estudo da narrativa. Calidoscópio, São Leopoldo, v. 3, n. 2, p. 74-87, 2005. 
76-85, 2008.

Diante do sofrimento do outro. Calidoscópio, São Leopoldo, v. 6, n. 2, p.

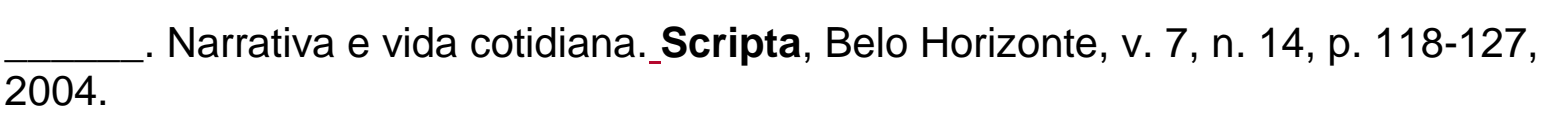

DENZIN, N. K.; LINCOLN, Y. S. Introdução: a disciplina e a prática da pesquisa qualitativa. In: DENZIN, N. K.; LINCOLN, Y. S. (org.) O planejamento da pesquisa qualitativa. Teorias e abordagens. Porto Alegre: Artmed, 2006. p. 15-42.

DINIZ-PEREIRA, J. E.; ZEICHNER, K. M. Justiça Social: desafio para formação de professores. Tradução: Cristina Antunes. Belo Horizonte: Autêntica Editora, 2008.

ERICKSON, F. Qualitative Methods in Research on Teaching. In: WITTROCK, M. C. (ed.) Handbook of Research on Teaching. New York: Macmillan, 1986.

FOUCAULT, M. The Subject and Power. In: DREYFUS, H. L.; RABINOW, P. Michel Foucault: Beyond Structuralism and Hermeneutics. Chicago: The University of Chicago Press, 1982. p. 208-226.

GOFFMAN, E. Frame Analysis. New York: Harper and Row, 1974.

GUBA, E. G.; LINCOLN, Y. Competing Paradigms in Qualitative Research. In: DENZIN, N.; LINCOLN, Y. Handbook of Qualitative Research. Thousand Oaks: SAGE Publications, 1994. p. 105-117.

HOUAISS, A. Dicionário Houaiss da língua portuguesa. Rio de Janeiro: Ed. Objetiva, 2001.

LABOV, W. The Transformation of Experience in Narrative Syntax. In:

Language in the Inner City. Philadelphia: University of Pennsylvania Press, 1972.

.; WALETZKY, J. Narrative Analysis: Oral Versions of Personal Experience. In: PAULSTON, C.; TUCKER, G. (ed.). Sociolinguistics - the Essential Readings. Oxford: Blackwell, 2003. p. 74-104.

LINCOLN, Y.; GUBA, E. G. Controvérsias paradigmáticas, contradições e confluências emergentes. In: DENZIN, N. K.; LICOLN, Y. S. (org.). O planejamento da pesquisa qualitativa. Teorias e abordagens. Porto Alegre: Artmed, 2006. p. 169192.

LINDE, C. Life Stories, the Creation of Coherence. New York: Oxford University Press, 1993.

MILLER, I. K. A Prática Exploratória na educação continuada de professores de línguas: inserções acadêmicas e teorizações híbridas. In: SILVA, K. A. da; DANIEL, F. de G.; KANEKO-MARQUES, S. M.; SALOMÃO, A. C. B. (org.) A formação de professores de línguas: Novos Olhares. São Paulo: Pontes Editores, 2012. v. 2. 
. Construindo Parcerias Universidade-Escola: Caminhos Éticos e Questões Crítico-Reflexivas. In: GIMENEZ, T.; GÓES MONTEIRO, M. C. de. (org.). Formação de professores de línguas na América Latina e transformação social. Campinas: Pontes Editores, 2010. p. 109-129. v. 4.

MINAYO, M. C. S. (org.). Pesquisa social - Teoria, método e criatividade. Petrópolis: Editora Vozes, 2002.

MORAES BEZERRA, I. C. "Com quantos fios se tece uma reflexão?” narrativas e argumentações no tear da interação. Rio de Janeiro: Departamento de Letras, PUC-Rio, Tese de Doutorado, 2007.

RIBEIRO, B. T.; BASTOS, L. C. Telling Stories in Two Psychiatric Interviews: a Discussion on Frame and Narrative. AlLA Review, Amsterdam/Philadelphia, v. 18, p. 58-75, 2005.

RIBEIRO, B. T.; GARCEZ, P. M. (org.). Sociolinguística interacional. 2. ed. São Paulo: Loyola, 2002.

VAN DIJK, T. A. Discurso e Poder. São Paulo: Contexto, 2008.

\section{Sobre a autora}

\section{Gysele da Silva Colombo Gomes}

Gysele da Silva Colombo Gomes possui graduação em Letras Português-Inglês pela Universidade do Estado do Rio de Janeiro (1990), mestrado em Linguística Aplicada pela Pontifícia Universidade Católica de São Paulo (2006) e é doutora em Estudos da Linguagem pela Pontifícia Universidade Católica do Rio de Janeiro (2014). Atualmente é professora adjunta da Universidade do Estado do Rio de Janeiro (UERJ). Tem experiência na área de Letras, com ênfase em Língua Inglesa, atuando principalmente nos seguintes temas: tendências e abordagens no ensino de línguas estrangeiras; o aprendiz e zona de conforto; conscientização das competências do professor de LE; ensino-aprendizagem, crenças, interação e autonomia na sala de aula; discurso e práticas sociais; alinhamentos, identidades e trabalhos da face; letramentos multiculturais; reflexão; entendimentos e Prática Exploratória. Desenvolve seu trabalho principalmente nas seguintes áreas: Formação Inicial e Continuada de Professores de Língua Inglesa e Ensino de Língua Inglesa. 